\title{
An investigation of lead absorption in an electric accumulator factory with the use of personal samplers
}

\author{
M. K. WILLIAMS, E. KING, AND JOAN WALFORD \\ The TUC Centenary Institute of Occupational Health, \\ London School of Hygiene and Tropical Medicine, Keppel Street, London, W.C.1 \\ and the Department of Occupational Health, University of Manchester
}

\begin{abstract}
Williams, M. K., King, E., and Walford, Joan (1969). Brit. J. industr. Med., 26, 202-216. An investigation of lead absorption in an electric accumulator factory with the use of personal samplers. Thirty-nine lead workers and controls, in stable conditions of exposure, each wore personal lead-in-air samplers daily for two weeks. During the second week samples for blood lead, urinary lead, urinary coproporphyrin, urinary $\delta$-aminolevulinic acid (ALA), the punctate basophil count, and haemoglobin were taken daily. Duplicate estimations were made on one day.

The lead exposures of men doing almost identical jobs differed by ratios of up to four to one. This could be attributed only to personal differences in working habits.

The correlation coefficients and regression equations of the biochemical tests with lead-inair and with each other were determined. The mean values and $95 \%$ confidence limits of single determinations of some of the biochemical tests corresponding to the two commonly accepted TLVs of lead-in-air $\left(0.20\right.$ and $\left.0.15 \mathrm{mg} . / \mathrm{m}^{3}\right)$ were calculated from the regression equations.

For each biochemical test the variation due to analytical error, the variation from day to day within subjects and the residual variation about the regression on lead-in-air were calculated. Previous estimates of the latter are not known. Excessive confidence may be placed in an index of exposure due to its low coefficient of variation within subjects unless the coefficient of variation between subjects about regression is taken into account.

The correction for specific gravity of estimations of lead and ALA in spot samples of urine was found to reduce slightly the residual variation between subjects about the regression on lead-in-air and to increase the correlations with lead-in-air and with the other biochemical tests, but these changes were not statistically significant.

The modified method used for estimating blood lead and urinary lead is described and validated.
\end{abstract}

Differences between men in susceptibility to lead have been attributed to personal differences in working habits as well as to personal differences in the metabolic effect of the lead absorbed. The magnitude of such personal differences in working habits appears to be unknown (Legge and
Goadby, 1912; Hamilton, 1919; Lane, 1949; Kehoe, 1962).

Many writers have found an association between biochemical tests of lead absorption and lead-in-air concentration, but regression equations and estimates of some of the sources of variation of the biochemical 
tests are not known (e.g., Dreessen et al., 1941; Elkins, 1959; Kehoe, 1961).

The benefit obtained from correcting urinary lead estimations for specific gravity is controversial (Barnes, 1939; Levine and Fahy, 1945; Molyneux, 1964; Elkins and Pagnotto, 1965; Ellis, 1966).

Further information has been obtained from a survey of lead workers.

\section{The survey}

The survey was made in a lead-acid battery factory. Personal samplers (Casella \& Co., 1966; Williams, Walford, and King, 1968) were worn on the coat lapel by a number of workers every shift for two weeks to obtain accurate estimates of the lead-in-atmosphere concentration to which they were exposed. During the second week blood lead, urinary lead, urinary coproporphyrin, urinary ALA, the punctate basophil count, and haemoglobin were estimated daily, and the estimates on one day were duplicated. Lead workers were sought whose lead exposure was fairly constant and had continued long enough for the biochemical tests to be reasonably stable. The selection criteria adopted were that there had been no change of job within the last year, no recent sickness, holiday or other absence, and no change in overtime or in productivity for six months. The jobs of men selected represented the full range of lead exposure available and did not entail wearing respirators. Of the men in the factory who fulfilled these criteria, the following 40 were chosen: all the six machine pasters (M), all the eight hand pasters $(\mathrm{H})$, all the six hand casters $(\mathrm{C})$ on day work, the first 10 to volunteer of the 15 forming men (F), and the first 10 to volunteer of 18 controls (O) on one shift in two departments (A and B) making plastics. No assembly men were selected because their jobs - and lead exposure - changed frequently. Charging men and machine casters were not included because their lead exposures differed little from those of the controls and hand casters respectively. The element of self-selection in the forming men and controls was thought to be unimportant because the men knew there was no likelihood of their job or their wages being affected, or an illness discovered, as a result of entering the survey. The jobs have been described in detail elsewhere (Williams, 1967).

The men were studied in four groups of 10 . Each man wore one of 10 personal samplers for the whole of each shift, from clocking in to clocking out, including meal breaks and smoke breaks. When changing clothes the sampler was left running near by. Different samplers were worn daily in a randomized sequence. If any sampler failed it was replaced by a spare. At the end of the day the personal sampler filter discs were renewed, the hour meters read, the speeds timed, and the flows calibrated against a standard Gap rotameter (Chloride Technical Services - personal communication) and adjusted where necessary to give a reading within the range $2.0 \pm 0.21 . / \mathrm{min}$. (Williams, 1967). A rotameter flowmeter reads high when the flow - like that of the personal samplers - is pulsating. When the flows of six personal samplers, adjusted to give readings on the Gap rotameter in the range $2.00 \pm 0.051 . / \mathrm{min}$., were each measured 10 times by means of the null-point method described by Roach (1966a), the mean flow rates of the personal samplers ranged from 1.43 to 1.651 ./min., with an overall mean of $1.541 . / \mathrm{min}$. Calculations are based on the figure of $1.541 . / \mathrm{min}^{1}$

During the second week, samples for blood lead (by venepuncture), urinary lead, punctate basophil count, and haemoglobin were collected daily between 1000 and 1100 hours. Another urinary sample for coproporphyrin and ALA was collected daily between 1200 and 1300 hours. To avoid urinary lead samples of low specific gravity, the men were requested to limit their fluid intake before sampling to half a pint the previous night and one cupful for breakfast. Before the urinary lead and blood samples were taken the men washed and changed out of working clothes. The collection of urinary lead samples was supervised by a first-aid attendant. A 5-ml. blood sample for lead estimation was taken with a disposable plastic syringe and de-leaded polythene bottle containing anti-coagulant by one of us (M.K.W.). One experienced State Registered Nurse made a blood slide for punctate basophil count and took a sample for haemoglobin estimation with a 0.02-ml. blood pipette.

Lead-in-air samples were estimated polarographically, and blood lead and urinary lead samples were analysed by the method given in the Appendix, by one of us (E.K.). Urinary coproporphyrin was estimated using the semiquantitative method of Donath (1956), and urinary ALA using a simplification (Williams and Few, 1967) of the method of Mauzerall and Granick (1956), by one of us (M.K.W.). Punctate basophil counts were made by one experienced technician using Malcolm's (personal communication) modification of Lane's (1949) method. Haemoglobin estimations were undertaken by the experienced State Registered Nurse using the M.R.C. grey wedge photometer which was calibrated before and after each weekly group of observations. The specific gravity of the urine samples was measured by hydrometer.

Duplicate estimations were made of the biochemical tests on Wednesdays. For the punctate basophil count and haemoglobin duplicate samples were taken, one from each ear, and estimated 'blind'. For the other biochemical tests it was thought that sampling errors would be small compared to analytical errors, and that duplicate urinary samples might have low volumes, so duplicate estimations of single samples were made.

\section{Results}

Of the $\mathbf{4 0}$ men studied, one withdrew after eight days due to a foot injury. The results obtained from the remaining 39 men were as follows.

\section{Personal samplers}

Of the 390 total possible lead-in-air results, 387 were accepted. Two lead-in-air samples from a control were missed due to sickness absence, and one lead-inair result was more than 10 standard deviations higher than the mean of the other nine samples from the same man and so was rejected as unreliable.

IIn previous papers (Williams, King, and Walford, 1968a; Williams et al., 1968b) the figure of $2.01 . / \mathrm{min}$. was used. The concentrations of lead-in-air were therefore underestimated by $23 \%$. 
Differences in lead exposure between departments, between men, and between days were calculated in terms of the mass of lead found on the filter discs. For association with the biochemical tests, lead exposure was expressed as 'the mean eight-hour lead-in-air concentration', in $\mathrm{mg} . \mathrm{Pb} / \mathrm{m}^{3}$; the mean daily mass of lead in mg. found on each man's 10 filter discs was divided by $0.74 \mathrm{~m}^{3}$, the volume of air which would have been sampled in eight hours at $1.541 . / \mathrm{min}$.

\section{Biochemical tests}

Excluding the second estimation of the Wednesday duplicates, each of the biochemical tests had a possible total of 195 results.

The results from 144 of the blood samples were accepted, though one was collected two hours late owing to sickness absence. The samples from the men in the first group (comprising six casters and four hand pasters) were thought to be contaminated (Williams, 1967) and all 50 were rejected. Another batch of sample bottles was used for the remaining groups. One sample was lost during analysis.

The results from 182 urinary lead samples were accepted. One sample was missed due to sickness absence, one was lost during analysis, two results were rejected as contaminated, and nine had specific gravities less than 1.010 and were rejected (Barnes, 1939; Webster, 1941; Molyneux, 1964). Each urinary lead estimation was corrected to a standard specific gravity of 1.024 (Levine and Fahy, 1945; Elkins and Pagnotto, 1965). Corrected results are presented except where corrected and uncorrected results are compared.

Of the punctate basophil slides, 19 were reported as too dusty to read. The remainder were accepted.

None of the samples for urinary coproporphyrin and ALA, or for haemoglobin, was missed. All the results were accepted. The urinary coproporphyrin and ALA results presented have not been corrected for specific gravity, except where corrected and uncorrected results of urinary ALA are compared.

The mean values of the biochemical tests of each man were calculated from his daily results, using the first estimation of the Wednesday duplicate estimations except in the case of the 'dusty' punctate basophil counts, where the first missing result of any man was replaced by the result of his second duplicate.

\section{Differences in lead exposure}

\section{Between departments}

The mean daily mass of lead found on the filter discs in each department was calculated. There were highly significant differences $(P<0.001)$ between all departments except plastics departments $A$ and B $(0.02<\mathrm{P}<0.05)$ and between forming and hand pasting where the difference was not significant (Table 1).

\section{Between men}

Analyses of variance of the daily mass of lead found on the filter discs were carried out to test overall differences between individual men within departments. Highly significant differences $(P<0.001)$ were found between machine pasters, between hand pasters, and between forming men. No significant differences were found between men in other departments.

In departments where overall differences were statistically significant, the individual differences between pairs of men within the departments were tested for significance by the Newman Keuls method using the studentized range. This method was used because comparisons between specific individuals were not planned in advance, and if the ordinary $t$-test is used to test large numbers of differences some significant results are likely to occur by chance.

Table 2 shows the significance of the differences of the mean daily mass of lead found on the filter discs of machine pasters, hand pasters, and forming men.

\section{Between days}

Analyses of variance showed differences between days to be very significant $(0.001<P<0.01)$ in casting and significant $(0.01<P<0.05)$ in forming but not significant in machine pasting and plastics

TABLE 1

Mean Daily Mass of Lead (mg. Pb) on Filter Discs in Each Department and Significance OF DifFerences between Departments

\begin{tabular}{|c|c|c|c|c|c|c|c|c|c|c|c|}
\hline & Dep & men & & & & $m g . P b$ & Plastics & Plastics & Casting & Forming & Hand \\
\hline $\begin{array}{l}\text { Machine pasting } \\
\text { Hand pasting } \\
\text { Forming } \\
\text { Casting } \\
\text { Plastics Dept. A } \\
\text { Plastics Dept. B }\end{array}$ & $\begin{array}{l}\cdots \\
\cdots \\
\cdots \\
\cdots \\
\cdots\end{array}$ & $\begin{array}{l}\cdots \\
\cdots \\
\cdots \\
\cdots \\
\cdots\end{array}$ & $\begin{array}{l}\cdots \\
\cdots \\
\cdots \\
\cdots \\
\cdots\end{array}$ & $\begin{array}{l}\cdots \\
\cdots \\
\cdots \\
\cdots \\
\cdots\end{array}$ & $\begin{array}{l}\cdots \\
\cdots \\
\cdots \\
\cdots \\
\cdots\end{array}$ & $\begin{array}{l}0.160 \\
0.110 \\
0.099 \\
0.038 \\
0.0087 \\
0.0064\end{array}$ & $\begin{array}{l}* * \\
* * \\
* * \\
* * \\
*\end{array}$ & $\begin{array}{l}* * \\
* * \\
* * \\
* *\end{array}$ & $\begin{array}{l}* * \\
* * \\
* *\end{array}$ & $\begin{array}{c}* * \\
\text { NS }\end{array}$ & $* *$ \\
\hline
\end{tabular}

** $=$ P $<0.001 \quad *=0.02<\mathrm{P}<0.05 \quad \mathrm{NS}=$ not significant. 
department A. Hand pasting and plastics department $B$ were not tested because some values were missing.

\section{Discussion}

Standardization for exposure time In defining 'threshold limit value' the American Conference of Governmental Industrial Hygienists (1960) referred to 'the normal workday'. Tsuchiya and Harashima (1965) derived TLVs from a study of Japanese lead workers working between 48 and 60 hours a week. In the present survey the men worked a 40-hour week. Because lead has a biological half-life of several months (Roach, 1966b), results may therefore differ by a factor of $50 \%$ unless allowance is made for the length of weekly exposure. In the absence of an agreed known standard, the present lead-in-air concentrations were calculated as the time-weighted average concentration standardized to an eight-hour day, five-day week.

In routine practice it may be inconvenient for samplers to be worn other than at the workbench. Lead exposure during washing, changing, canteen breaks, etc. is thought to be low, but the time spent on these activities may constitute as much as three hours in an eight-hour shift (Williams et al., 1968b). Thus substantial errors in estimating the 'eight-hour shift exposure' may be made from readings taken only at the workbench unless time spent away from the workbench is known.

Differences between departments Dreessen and his colleagues (1941) using static samplers investigated six electric accumulator factories. Mean readings of lead-in-air concentration when exhaust ventilation

TABLE 2

Significance of Differences between Mean Daily Mass of Lead (mg. Pb) on Filter Discs of Machine Pasters, Hand Pasters, and Forming Men

Machine pasters

\begin{tabular}{c|c|c|c|c|c|c|c}
\hline Man & $m g . P b$ & $F$ & $E$ & $D$ & $C$ & $B$ & \\
\hline A & 0.217 & $* *$ & $* *$ & NS & NS & NS & \\
B $^{1}$ & 0.183 & $* *$ & $* *$ & NS & NS & & \\
D & 0.173 & $* *$ & $*$ & NS & & & \\
E & 0.173 & $* *$ & $*$ & & & & \\
F & 0.095 & NS & & & & & \\
\hline
\end{tabular}

1 = leading hand.

Hand pasters

\begin{tabular}{c|c|c|c|c|c|c|c|c}
\hline Man & $m g . P b$ & $H$ & $G$ & $F$ & $E$ & $D$ & $C$ & $B$ \\
\hline A & 0.220 & $* *$ & $* *$ & $* *$ & $* *$ & $* *$ & $* *$ & NS \\
B & 0.172 & $* *$ & $* *$ & $* *$ & $* *$ & NS & NS & \\
C & 0.123 & NS & NS & NS & NS & & & \\
D & 0.118 & NS & NS & NS & NS & & & \\
F & 0.077 & NS & NS & NS & & & & \\
G & 0.071 & NS & NS & & & & & \\
H & 0.051 & NS & & & & & & \\
\hline
\end{tabular}

Forming men

\begin{tabular}{c|c|c|c|c|c|c|c|c|c}
\hline Man & $m g . P b$ & $I$ & $H$ & $G$ & $F$ & $E$ & $D$ & $C$ & $B$ \\
\hline A & 0.148 & $* *$ & $* *$ & $* *$ & $* *$ & $*$ & NS & NS & NS \\
B & 0.130 & $* *$ & $* *$ & $*$ & NS & NS & NS & NS & \\
C & 0.117 & $*$ & $*$ & NS & NS & NS & NS & & \\
D & 0.108 & NS & NS & NS & NS & NS & & & \\
E & 0.097 & NS & NS & NS & NS & & & \\
F & 0.089 & NS & NS & NS & & & & \\
G & 0.083 & NS & NS & & & & & \\
H & 0.062 & NS & & & & & & & \\
I & 0.059 & & & & & & & & \\
\hline
\end{tabular}

$* *=P<0.01 \quad *=0.01<P<0.05 \quad$ NS $=$ not significant. 
TABLE 3

Departmental Means, and Standard Errors, of Biochemical Tests and Eight-hour LeAD-IN-AIR CONCENTRATIONS, AND Numbers OF MEN IN EACH Department

\begin{tabular}{|c|c|c|c|c|c|c|c|c|c|c|c|c|c|c|}
\hline Job & $n$ & \multicolumn{2}{|c|}{$\begin{array}{l}\text { Pb-in-air } \\
\left(\text { mg./m. }{ }^{3}\right)\end{array}$} & \multicolumn{2}{|c|}{$\begin{array}{c}B L \\
(\mu g . / 100 \mathrm{ml} .)\end{array}$} & \multicolumn{2}{|c|}{$\underset{(\mu g . / l .)}{U L}$} & \multicolumn{2}{|c|}{$\begin{array}{c}U C P \\
\text { (Donath) }\end{array}$} & \multicolumn{2}{|c|}{$\begin{array}{c}A L A \\
(m g . / 100 \mathrm{ml} .)\end{array}$} & \multicolumn{2}{|c|}{$\begin{array}{c}P B C \\
\left(P B C / 10^{\circ} R B C\right)\end{array}$} & $\begin{array}{c}H b \\
(\%) \\
\text { Mean S.E. }\end{array}$ \\
\hline $\begin{array}{l}\text { Machine pasting } \\
\text { Hand pasting } \\
\text { Forming } \\
\text { Casting } \\
\text { Plastics dept. A } \\
\text { Plastics dept. B }\end{array}$ & $\begin{array}{l}6 \\
8 \\
9 \\
6 \\
5 \\
5 \\
5\end{array}$ & $\begin{array}{l}0.218 \\
0.150 \\
0.134 \\
0.052 \\
0.012 \\
0.009\end{array}$ & $\begin{array}{l}0.025 \\
0.029 \\
0.013 \\
0.003 \\
0.0008 \\
0.0008\end{array}$ & $\begin{array}{l}74 \cdot 2 \\
63 \cdot 2 \\
63 \cdot 0 \\
\overline{27 \cdot 2} \\
29 \cdot 1\end{array}$ & $\begin{array}{r}4 \cdot 7 \\
9 \cdot 2 \\
2 \cdot 7 \\
-1 \cdot 4 \\
1 \cdot 6\end{array}$ & $\begin{array}{r}163 \cdot 8 \\
111 \cdot 3 \\
114.0 \\
87 \cdot 9 \\
34 \cdot 5 \\
34 \cdot 8\end{array}$ & $\begin{array}{r}21 \cdot 2 \\
14 \cdot 1 \\
7 \cdot 2 \\
6 \cdot 8 \\
3 \cdot 2 \\
2 \cdot 0\end{array}$ & $\begin{array}{l}4 \cdot 6 \\
3 \cdot 2 \\
3 \cdot 8 \\
1 \cdot 8 \\
1 \cdot 8 \\
2 \cdot 3\end{array}$ & $\begin{array}{l}0 \cdot 49 \\
0 \cdot 37 \\
0 \cdot 38 \\
0 \cdot 11 \\
0 \cdot 18 \\
0 \cdot 26\end{array}$ & $\begin{array}{l}2.29 \\
0.87 \\
1.43 \\
0.75 \\
0.56 \\
0.59\end{array}$ & $\begin{array}{l}0.58 \\
0 \cdot 11 \\
0.27 \\
0.05 \\
0.08 \\
0.08\end{array}$ & $\begin{array}{l}5,578 \\
3,291 \\
2,430 \\
2,840 \\
1,728 \\
2,104\end{array}$ & $\begin{array}{r}1,664 \\
532 \\
378 \\
492 \\
440 \\
220\end{array}$ & $\begin{array}{ll}106 \cdot 1 & 1 \cdot 10 \\
108 \cdot 6 & 1 \cdot 82 \\
103 \cdot 9 & 0 \cdot 78 \\
104 \cdot 3 & 2 \cdot 61 \\
104 \cdot 4 & 1 \cdot 97 \\
103 \cdot 3 & 0.84\end{array}$ \\
\hline
\end{tabular}

$\mathrm{BL}=$ blood lead, $\mathrm{UL}=$ urinary lead, $\mathrm{UCP}=$ urinary coproporphyrin, $\mathrm{ALA}=$ urinary $\mathrm{ALA}, \mathrm{PBC}=$ punctate basophil count.

was in operation, as in the present investigation, were: machine pasting $0.49 \mathrm{mg} . \mathrm{Pb} / \mathrm{m}^{3}{ }^{3}$, hand pasting $0.21 \mathrm{mg} . \mathrm{Pb} / \mathrm{m}^{3}$, and hand casting 0.09 $\mathrm{mg}$. $\mathrm{Pb} / \mathrm{m}^{3}$. Forming departments averaged 0.04 mg. $\mathrm{Pb} / \mathrm{m}^{3}$. The first three results are greater, and the fourth less, than those found in the present survey (Table 3). Such differences might be caused by differences between personal and static sampling.

Differences between men Differences between men in susceptibility to lead have been widely discussed and have been attributed to personal differences in working habits as well as to personal differences in the metabolic effects of lead absorbed (Legge and Goadby, 1912; Hamilton, 1919; Lane, 1949; Kehoe, 1962). However, objective evidence of such differences in working habits between men doing similar jobs is not known.

In the present survey, machine pasters - excluding leading hands - rotated jobs equally several times daily and rotated between the two machines weekly. Hand pasters changed plate type and bench position daily, and were paid according to the numbers of plates pasted, up to a weekly maximum - a 'medical ceiling' - which all men achieved. The foreman of the forming department said he allocated jobs equally among all forming men. These men were on piece-work and would have objected if the work had not been allocated fairly, and there was no marked difference in their earnings. Thus differences in lead exposure found between men within each of these three departments were probably due to differences in individual working methods and not to differences in type and quantity of work dope. Differences between hand pasters have also been found in a previous investigation (Williams et al., 1968b).The absence of differences between men in the casting and plastics departments suggests that lead exposure in these departments depends on the general atmosphere rather than on personal working methods.

It can be seen from Table 2 that in machine pasting the exposure of the 'dirtiest' worker is twice that of the 'cleanest', in hand pasting the ratio is four to one, and in forming the ratio is two-and-ahalf to one. All these men were selected as suitable for lead work at pre-employment interviews by personnel and medical departments from highquality applicants. Subjective ranking by their respective foremen of hand pasters and forming men for 'cleanliness of working' was compared with the results of objective ranking based on the personal sampler results. Spearman-Rank correlation coefficients of 0.67 and 0.79 respectively were obtained. Since the numbers of men were small, the former figure is not statistically significant, but the latter figure is significant at the 0.01 level, which suggests that selection has value. An unselected population would therefore be expected to show even greater differences between men than those demonstrated.

Differences between days Differences in lead exposure between days were also found in a previous investigation of hand-pasters (Williams et al., 1968b). The cause of these differences is unknown.

\section{The biochemical tests and lead exposure}

\section{Differences in the biochemical tests between} departments

The mean values of the biochemical tests and lead-inair concentrations in each department, and the standard errors of the means, are shown in Table 3. The departmental means of all the biochemical tests except haemoglobin vary with the mean lead-in-air. It can be seen that the statistical significance of differences between departments is much greater for some biochemical tests than for others. The differences in mean punctate basophil count, for example, are relatively small.

Associations of the biochemical tests with lead exposure

Scatter diagrams were made by plotting the coordi- 
nate points of the individual men's mean values of the biochemical tests with the mean eight-hour lead-in-air concentration as shown in Figure 1. The scatter diagrams suggested that all the biochemical tests except haemoglobin were positively correlated with lead-in-air.

The linearity of the regression of each biochemical test on lead-in-air was tested. None of the relationships was curvilinear at the $5 \%$ level of significance. The correlation coefficients and regression equations were calculated (Table 4), and the regression lines drawn on the scatter diagrams. All the correlation coefficients, except that of haemoglobin, were significantly greater than zero $(P<0.01)$. The regression equations of lead-in-air on the biochemical tests were calculated so that lead-in-air can be estimated from the biochemical tests.

\section{TABLE 4}

Correlation Coefficient (r) and Regression Equations (X, Y) OF Biochemical Test (y) WITH MEAN EIGHT-HOUR LEAD-IN-AIR CONCENTRATIONS (x) (mg./m. ${ }^{3}$ )

\begin{tabular}{|c|c|c|c|c|}
\hline$y$ & $r$ & & $\boldsymbol{Y}$ & $\boldsymbol{X}$ \\
\hline $\begin{array}{l}\text { BL } \\
\text { UL } \\
\text { UCP } \\
\text { ALA } \\
\text { PBC } \\
\text { Hb }\end{array}$ & $\begin{array}{l}0.90 \\
0.82 \\
0.82 \\
0.68 \\
0.45 \\
0.09\end{array}$ & $\begin{array}{l}30 \cdot 1 \\
45 \cdot 5 \\
1 \cdot 72 \\
0 \cdot 389 \\
1830 \\
1048\end{array}$ & $\begin{array}{l}+201 \mathrm{x} \\
+486 \mathrm{x} \\
+12 \cdot 5 \mathrm{x} \\
+6 \cdot 91 \mathrm{x} \\
+11300 \mathrm{x} \\
+\quad 4 \cdot 48 \mathrm{x}\end{array}$ & $\begin{array}{c}-0.0975+0.00399 y \\
-0.0277+0.00138 y \\
-0.0581+0.0540 y \\
0.0308+0.0668 y \\
0.0506+0.0000182 y \\
-0.0846+0.00181 y\end{array}$ \\
\hline
\end{tabular}

Abbreviations as in Table 3.

Values of the biochemical tests which correspond to the TLVs of lead-in-air

The maximum allowable concentrations (MACs) or threshold limit values (TLVs) commonly suggested for inorganic lead are $0.15 \mathrm{mg} . / \mathrm{m}^{3}$ (Russell, Jones, Bloomfield, Britten, and Thomson, 1933; Dreessen et al., 1941; the American Public Health Association, 1943b) and $0.20 \mathrm{mg} . / \mathrm{m}^{3}$ (Lane, 1931 ; Elkins, 1959 ; American Industrial Hygiene Association, 1960; the American Conference of Governmental Industrial Hygienists, 1965). The values of some of the biochemical tests which correspond to these values of lead-in-air were calculated from the regression equations. The $95 \%$ confidence limits of single determinations of the biochemical tests for each of the values of lead-in-air were also calculated, using as the variance the sum of the variance within subjects from day to day and the residual variance between the subjects' mean values about regression. The results are shown in Table 5. It can be seen that the $95 \%$ confidence limits of every biochemical test are very wide.

\section{Discussion}

Normal values The values of blood lead, urinary lead, and urinary coproporphyrin in the plastics departments where lead-in-air concentrations are low (Table 3 and Fig. 1) are consistent with values found in the normal population (Kehoe, 1961; Hofreuter, Catcott, Keenan, and Xintaras, 1961; Goldwater and Hoover, 1967; Watson and Larson, 1947; Haeger-Aronsen, 1960a; Zielhuis, 1961; Goldberg, Smith, and Lochhead, 1963).

The urinary ALA values of 0.56 and $0.59 \mathrm{mg} . / 100$ $\mathrm{ml}$. in the plastics departments are higher than the values of 0.29 and $0.20 \mathrm{mg} . / 100 \mathrm{ml}$. found in the normal population by Haeger-Aronsen (1960a) and Goldberg and his colleagues (1963) respectively. The present estimations were obtained by a simplified procedure in which the Dowex 2 stage was omitted and thus porphobilinogen, and possibly other Ehrlich chromagens, may have been retained by and eluted from the Dowex 50 (Williams and Few, 1967). This will not be important for screening lead workers for excessive urinary ALA, but will have increasing relative effect as ALA tends to zero and probably accounts for the high 'normal' level found here.

The punctate basophil count result of 2,000 $\mathrm{PBC} / 10^{6} \mathrm{RBC}$ is not comparable with previous values because there is no standard technique (American Public Health Association, 1943a;

TABLE 5

Mean Values and 95\% Confidence Limits of Single Determinations of the Biochemical Tests WHICH CORRESPOND TO THE TLVS OF LEAD-IN-AIR

\begin{tabular}{|c|c|c|c|c|c|}
\hline \multirow{2}{*}{$\begin{array}{c}T L V \\
\left(m g . P b / m .^{3}\right)\end{array}$} & & \multicolumn{4}{|c|}{ Biochemical test } \\
\hline & & $\begin{array}{c}B L \\
(\mu g . / 100 \mathrm{ml} .)\end{array}$ & $\begin{array}{c}U L \\
(\mu g . / l .)\end{array}$ & $\begin{array}{c}U C P \\
\text { (Donath) }\end{array}$ & $\begin{array}{c}A L A \\
(m g . / 100 ~ m l .)\end{array}$ \\
\hline $0 \cdot 20$ & $\begin{array}{c}\text { Mean } \\
95 \% \text { C.L. }\end{array}$ & $\begin{array}{c}70 \\
48-92\end{array}$ & $\begin{array}{c}143 \\
56-230\end{array}$ & $\begin{array}{c}4 \cdot 2 \\
2 \cdot 4-6 \cdot 0\end{array}$ & $\begin{array}{c}1 \cdot 8 \\
0 \cdot 3-3 \cdot 3\end{array}$ \\
\hline $0 \cdot 15$ & $\begin{array}{c}\text { Mean } \\
95 \% \text { C.L. }\end{array}$ & $\begin{array}{c}60 \\
38-82\end{array}$ & $\begin{array}{c}118 \\
31205\end{array}$ & $\begin{array}{c}3.6 \\
1.8-5.4\end{array}$ & $\begin{array}{c}1 \cdot 4 \\
-0 \cdot 1-2 \cdot 9\end{array}$ \\
\hline
\end{tabular}

Abbreviations as in Table 3. 
(a)

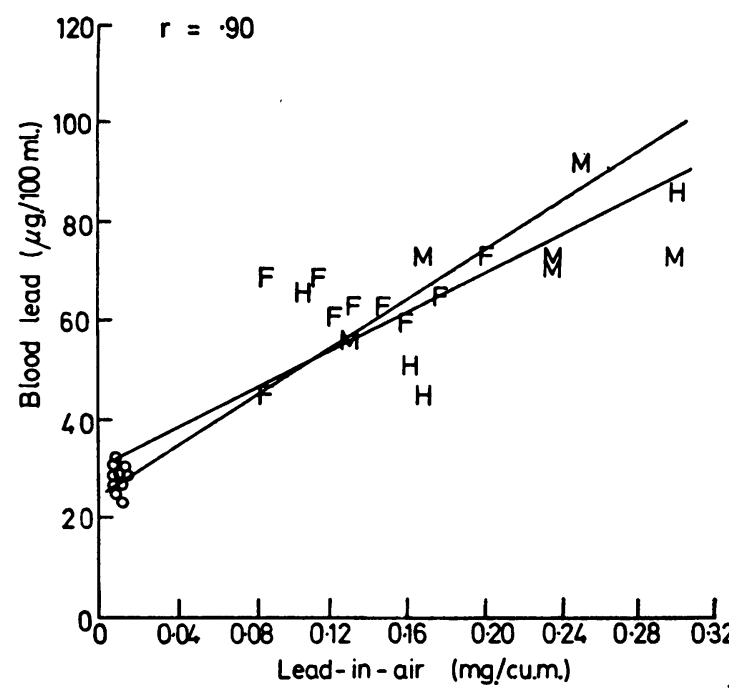

(b)

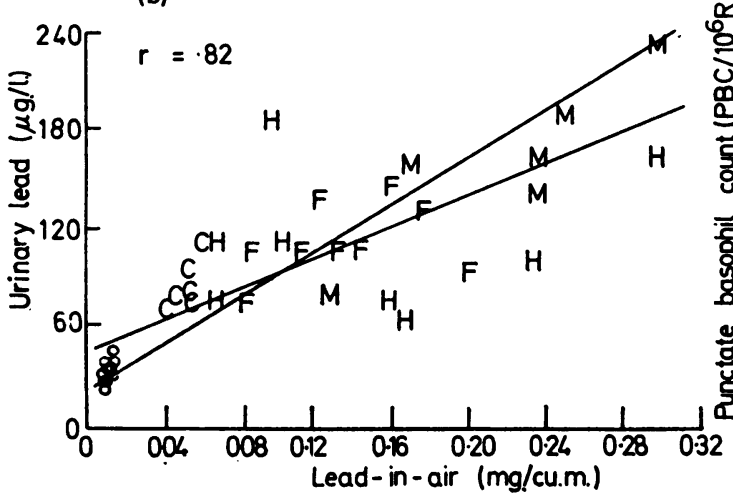

(c)

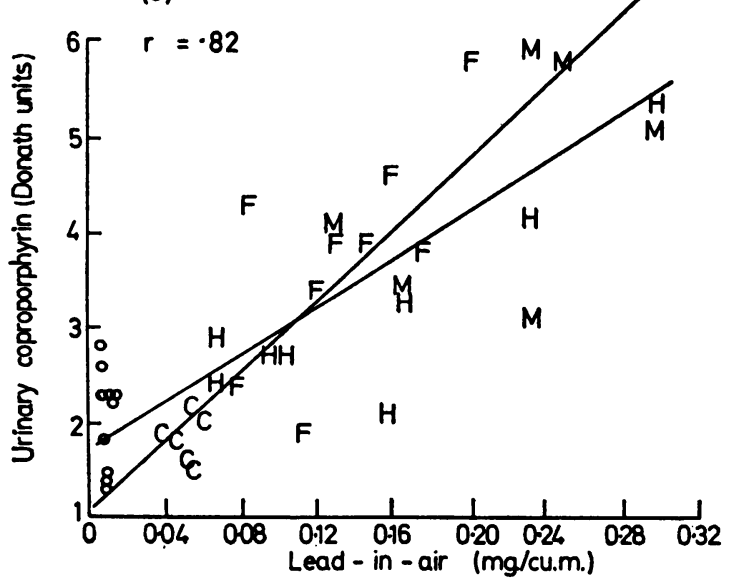

(d)

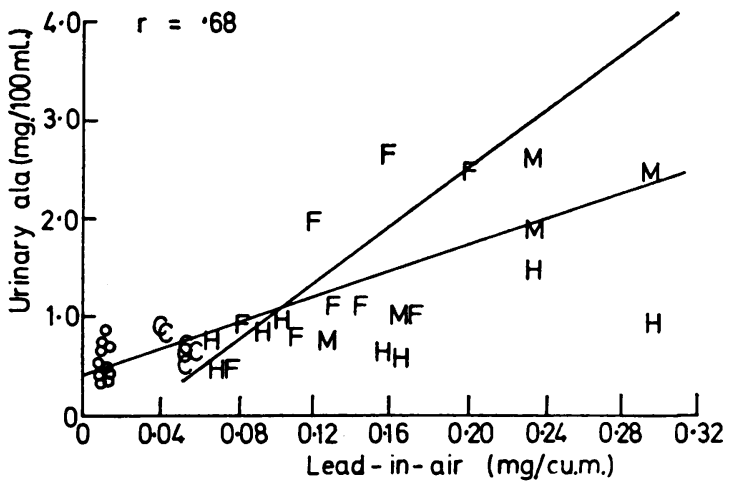

(e)

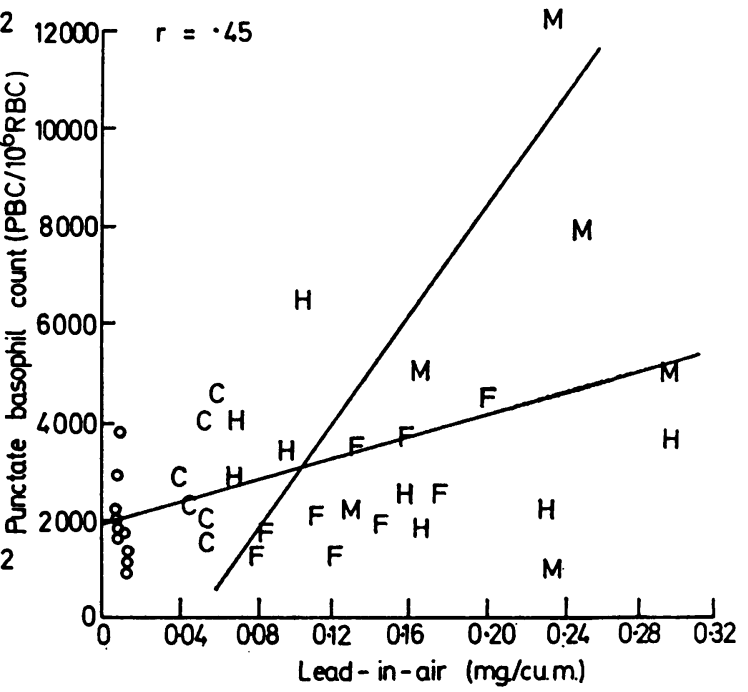

(f)

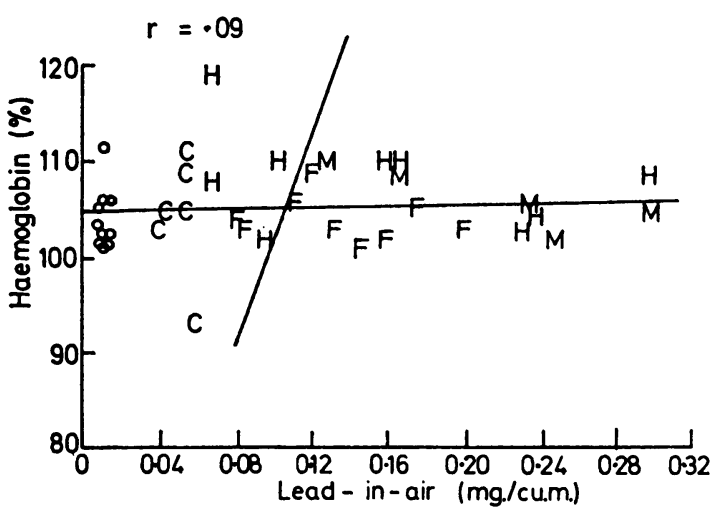

FIG. 1. Associations of the biochemical tests with lead exposure. Scatter diagrams made by plotting the individual mean values of each biochemical test with the mean eight-hour lead-in-air concentration. Values are plotted as the initial letter of the man's department, excepting values from the plastics departments which are shown as noughts. Regression lines and correlation coefficients (r) are also shown.

(a) Blood lead; (b) Urinary lead; (c) Urinary coproporphyrin; (d) Urinary ALA; (e) Punctate basophil count; (f) Haemoglobin. 
Lane, 1949; Shiels, Palmer, Cornish, and Kearley, 1953; Zielhuis, 1958).

The mean haemoglobin of all workmen was $105 \%$ Haldane, or 15.5 g. $/ 100 \mathrm{ml}$. $(100 \%=14.8 \mathrm{~g} . / 100$ ml.). Documenta Geigy (1962) gives a mean of about $16.0 \mathrm{~g} . / 100 \mathrm{ml}$. for peripheral venous blood in males, and states that the exact figure depends on the haemoglobinometer used.

Associations of the biochemical tests with lead exposure Lead absorption may be influenced not only by lead exposure - estimated here by personal sampler - but also by such factors as the respiratory minute volume of the man and the particle size and solubility of the lead dust to which he is exposed. Figure 1 does not indicate any marked departmental differences. In only one instance - the urinary lead of casters - does the biochemical test of every man within a department lie on one side of the regression line on lead-in-air concentration. This instance might arise from differences in particle size or respiratory minute volume, but the other biochemical tests of the casters would then be expected to show a similar deviation, which they do not. It appears that differences between departments in these factors are either small or cancel out. This finding is consistent with Elkins' (1959) belief that only extremely insoluble and coarse particles influence the hazard.

Correlation coefficients and regression equations of the biochemical tests with lead exposure do not appear to have been published previously.

Corresponding values A lead-in-air of $0.20 \mathrm{mg} . / \mathrm{m} .{ }^{3}$ gives a corresponding blood lead of $70 \mu \mathrm{g} . / 100 \mathrm{ml}$. (Table 5). The latter is somewhat less than Kehoe's (1965) 'MAC' of $80 \mu \mathrm{g} . / 100 \mathrm{~g}$. but the upper $95 \%$ confidence limit of a single determination, 92 $\mu \mathrm{g} . / 100 \mathrm{ml}$., is considerably higher. Similarly, a lead-in-air of $0.2 \mathrm{mg} . / \mathrm{m}^{3}$ gives the following: a corresponding urinary lead of $143 \mu \mathrm{g}$./l., which is less than the value of $200 \mu \mathrm{g}$./1. expected by Elkins (1959) but is similar to Kehoe's (1962) 'safe mean' of $130 \mu \mathrm{g}$./l.; a corresponding urinary coproporphyrin of 4.2 Donath, somewhat below the level of 5 which Donath (1956) said indicated high lead absorption requiring blood lead and urinary lead estimation, and considerably less than the level of $1,000 \mu \mathrm{g}$./1. which Elkins (1959) said was a warning not to be ignored; and a corresponding urinary ALA of $1.8 \mathrm{mg}$./100 ml., somewhat above the figure of 1.5 mg./100 ml. which Cramér (1966) accepted as the 'hygienically permissible normal limit', and above the figure of $1.3 \mathrm{mg} . / 100 \mathrm{ml}$. which Haeger-Aronsen (1960b) found to be equivalent to a urinary lead of $150 \mu \mathrm{g} . / \mathrm{l}$. (Again, estimations of ALA using the method of Williams and Few (1967) may be slightly higher than those by the method of Mauzerall and
Granick (1956).) In every case the upper $95 \%$ confidence limit considerably exceeds the safe limit when a lead-in-air of $0.20 \mathrm{mg} . / \mathrm{m}^{3}$ is chosen, but approximates to it when a lead-in-air of $0.15 \mathrm{mg} . / \mathrm{m}^{3}$ is chosen. There is no reason to suppose that the $95 \%$ confidence limits are wide due to inadequacies in the data. Therefore several determinations of several tests should be made when accurate estimations of lead exposure are required.

\section{Sources of variation and inter-associations of the biochemical tests}

\section{Sources of variation}

Analyses of variance were carried out to examine the sources of variation of each biochemical test. The total variation of individual readings could be divided into the variation due to analytical error, the variation between subjects, and the variation from day to day within subjects.

\section{Analytical variation}

Analyses of variance of the duplicate estimations of the biochemical tests were carried out. Duplicate estimations of blood lead samples from the first group of men were included, three Wednesday duplicates - assumed to be contaminated - being replaced by Thursday duplicates. Urinary lead duplicates were not corrected for specific gravity.

There was no statistically significant difference in the mean value between the first and second estimation, except in the cases of blood lead and urinary coproporphyrin. Of the 38 blood lead pairs there was a mean increase of $1.66 \mu \mathrm{g} . / 100 \mathrm{ml}$. between the first and second readings, which was significant $(0.001<P<0.01)$. This could have been due to contamination of samples during removal of portions for the first estimations. Of the 39 urinary coproporphyrin pairs there was a mean decrease of 0.12 Donath units between the first and second readings, which was fairly significant $(0.01<P$ $<0.05$ ). This could have been due to deterioration of coproporphyrin from exposure to light during estimation (Holeček and Pěničkovà, 1957).

Estimations of the analytical variation, measured by the standard deviation and coefficient of variation, are shown for each biochemical test in Table 6, together with their standard errors. The coefficients of variation of haemoglobin and blood lead were small, those of urinary lead, coproporphyrin, and ALA were larger, and those of the punctate basophil count were very large.

\section{Between and within subjects variation}

Analyses of variance of the daily readings of each biochemical test were carried out. The variation between subjects was largely due to differences in 
TABLE 6

Sources of Variation of the Biochemical Tests: Analytical Variation, Variatiun within SubJects From Day to Day, and Residual Variation between SUbJects about the Regression on MEAN EIGHT-HOUR LeAD-IN-AIR CONCENTRATION

\begin{tabular}{|c|c|c|c|c|c|c|c|c|c|c|c|c|c|}
\hline \multirow{2}{*}{ Test } & \multirow{2}{*}{ Units } & \multicolumn{4}{|c|}{ Analytical variation } & \multicolumn{4}{|c|}{ Within subjects variation } & \multicolumn{4}{|c|}{$\begin{array}{c}\text { Between subjects variation } \\
\text { about regression }\end{array}$} \\
\hline & & $s$ & $S E(s)$ & $C V$ & $S E(C V)$ & $s$ & $S E(s)$ & $C V$ & $S E(C V)$ & $s$ & $S E(s)$ & $C V$ & $S E(C V)$ \\
\hline $\begin{array}{l}\text { BL } \\
\text { UL } \\
\text { UCP } \\
\text { ALA } \\
\text { PBC } \\
\text { Hb }\end{array}$ & $\begin{array}{l}\mu \mathrm{g} . / 100 \mathrm{ml} . \\
\mu \mathrm{g} . / 1 . \\
\text { Donath units } \\
\text { mg./100 ml. } \\
\text { PBC } / 10^{\circ} \mathrm{RBC} \\
\quad \%\end{array}$ & $\begin{array}{l}2 \cdot 7 \\
7 \cdot 9 \\
0 \cdot 22 \\
0 \cdot 09 \\
950 \\
2 \cdot 1\end{array}$ & $\begin{array}{l}0.3 \\
0.9 \\
0.02 \\
0.01 \\
140 \\
0.2\end{array}$ & $\begin{array}{r}4 \cdot 5 \\
10 \cdot 2 \\
7 \cdot 1 \\
7 \cdot 6 \\
30 \cdot 8 \\
2 \cdot 1\end{array}$ & $\begin{array}{l}0.5 \\
1.2 \\
0.8 \\
0.9 \\
4.5 \\
0.2\end{array}$ & $\begin{array}{c}5 \cdot 0 \\
31 \cdot 1 \\
0 \cdot 48 \\
0 \cdot 35 \\
1480 \\
3 \cdot 1\end{array}$ & $\begin{array}{l}0.3 \\
1 \cdot 8 \\
0.03 \\
0.02 \\
88 \\
0.2\end{array}$ & $\begin{array}{r}9 \cdot 3 \\
31 \cdot 9 \\
15 \cdot 9 \\
31 \cdot 1 \\
46 \cdot 5 \\
3 \cdot 0\end{array}$ & $\begin{array}{l}0.6 \\
1.9 \\
0.9 \\
1.8 \\
2.7 \\
0 \cdot 2\end{array}$ & $\begin{array}{c}21 \cdot 1 \\
65 \cdot 3 \\
1 \cdot 71 \\
1 \cdot 46 \\
4010 \\
9 \cdot 7\end{array}$ & $\begin{array}{l}2 \cdot 9 \\
7 \cdot 7 \\
0 \cdot 20 \\
0 \cdot 17 \\
466 \\
1 \cdot 13\end{array}$ & $\begin{array}{r}39 \cdot 4 \\
67 \cdot 1 \\
56 \cdot 1 \\
130 \cdot 8 \\
126 \cdot 0\end{array}$ & $\begin{array}{r}5 \cdot 4 \\
7 \cdot 8 \\
6 \cdot 5 \\
15 \cdot 2 \\
14 \cdot 7 \\
1 \cdot 1\end{array}$ \\
\hline
\end{tabular}

Abbreviations as in Table 3.

lead exposure and could be separated into two components, one due to the regression of the biochemical variable on lead-in-air, and the other the residual variation about the regression line. The regression coefficients had been calculated from the individual mean values, and to make the residual variation comparable with the variation within subjects the residual variance was multiplied by 5 when there were no daily readings of the biochemical test missing, and by a factor ranging from $4 \cdot 2$ to 4.9 when readings were incomplete. These factors were derived by dividing the between subjects sum of squares, calculated on single daily readings, by the between subjects sum of squares calculated from the individual mean values.

Table 6 shows for each biochemical test the variation within subjects from day to day and the residual variation between subjects about regression, expressed both as the standard deviation and as the coefficient of variation. The standard errors of both these measures of variation are also shown.

The within subjects coefficient of variation is very low for haemoglobin, intermediate for blood lead and urinary coproporphyrin, higher for urinary ALA and urinary lead, and highest for the punctate basophil count.

The between subjects coefficients of variation are higher. For haemoglobin it is small, for blood lead it is intermediate, for urinary coproporphyrin and urinary lead it is high, and for urinary ALA and the punctate basophil count it is very high.

Associations of the biochemical tests with each other Scatter diagrams (e.g., Fig. 2) were made by plotting the co-ordinate points of the individual men's mean values of pairs of the biochemical tests. The diagrams indicated that all the biochemical tests were positively associated with each other, with the exception of haemoglobin which did not appear to be associated with any of the other tests and is not shown.

Correlation coefficients for all pairs of tests were calculated and are shown in Table 7. Every correlation coefficient was significantly greater than zero $(P<0.01)$ with the exception of each of those of haemoglobin. Blood lead correlated well with urinary lead $(0.90)$ and decreasingly with urinary coproporphyrin (0.79), urinary ALA (0.68), and punctate basophilia $(0.54)$. The corresponding correlation coefficients of urinary lead were similar, except that with urinary coproporphyrin $(0.68)$ was slightly lower. Urinary coproporphyrin correlated most highly with blood lead (0.79) and urinary ALA $(0 \cdot 74)$. Punctate basophilia correlated most highly with urinary ALA (0.59). Haemoglobin correlated with nothing better than with blood lead $(0 \cdot 16)$, and this correlation coefficient was expected to be negative.

The regression equations were calculated for all possible pairs of tests with the exception of haemoglobin which was omitted because none of its correlation coefficients was significantly different from zero. The results are shown in Table 8. The regression lines drawn on the appropriate scatter diagrams are shown in Figure 2.

\section{Discussion}

Sources of variation The common belief that urinary lead and punctate basophilia have a high variability, and that blood lead has a low variability, is consistent with the findings of the within subjects variations, which is partly due to the analytical variation.

Previous estimates of residual variation of the biochemical tests between subjects about regression are not known. The present findings indicate that only haemoglobin has a low variation between 

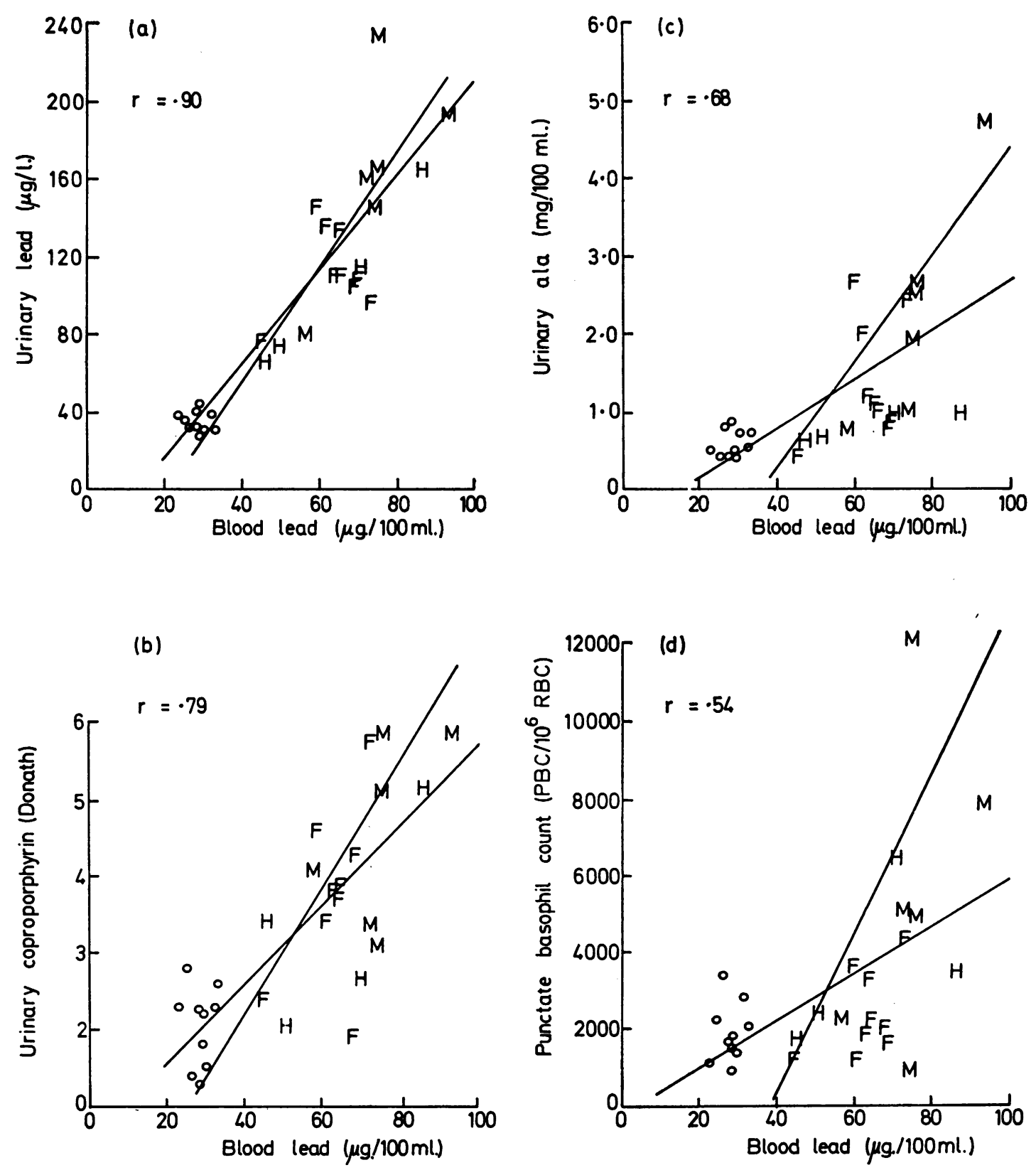

FIG. 2. Associations of biochemical tests with each other. Scatter diagrams made by plotting the individual mean values of pairs of biochemical tests. Values are plotted as the initial letter of the man's department, excepting values from the plastics departments which are shown as noughts. Regression lines and correlation coefficients are also shown.

(a) Blood lead and urinary lead; (b) Blood lead and urinary coproporphyrin; (c) Blood lead and urinary ALA; (d) Blood lead and punctate basophil count; (e) Urinary lead and urinary coproporphyrin; $(f)$ Urinary lead and urinary ALA; (g) Urinary lead and punctate basophil count; (h) Urinary coproporphyrin and ALA; (i) Urinary coproporphyrin and punctate basophil count; (j) Urinary ALA and punctate basophil count. 
(e)

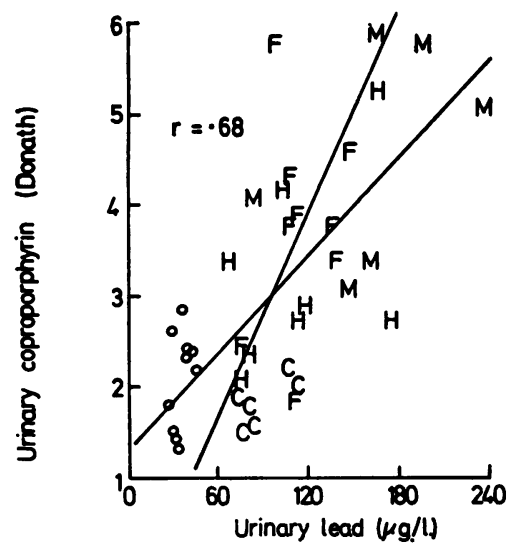

(f)
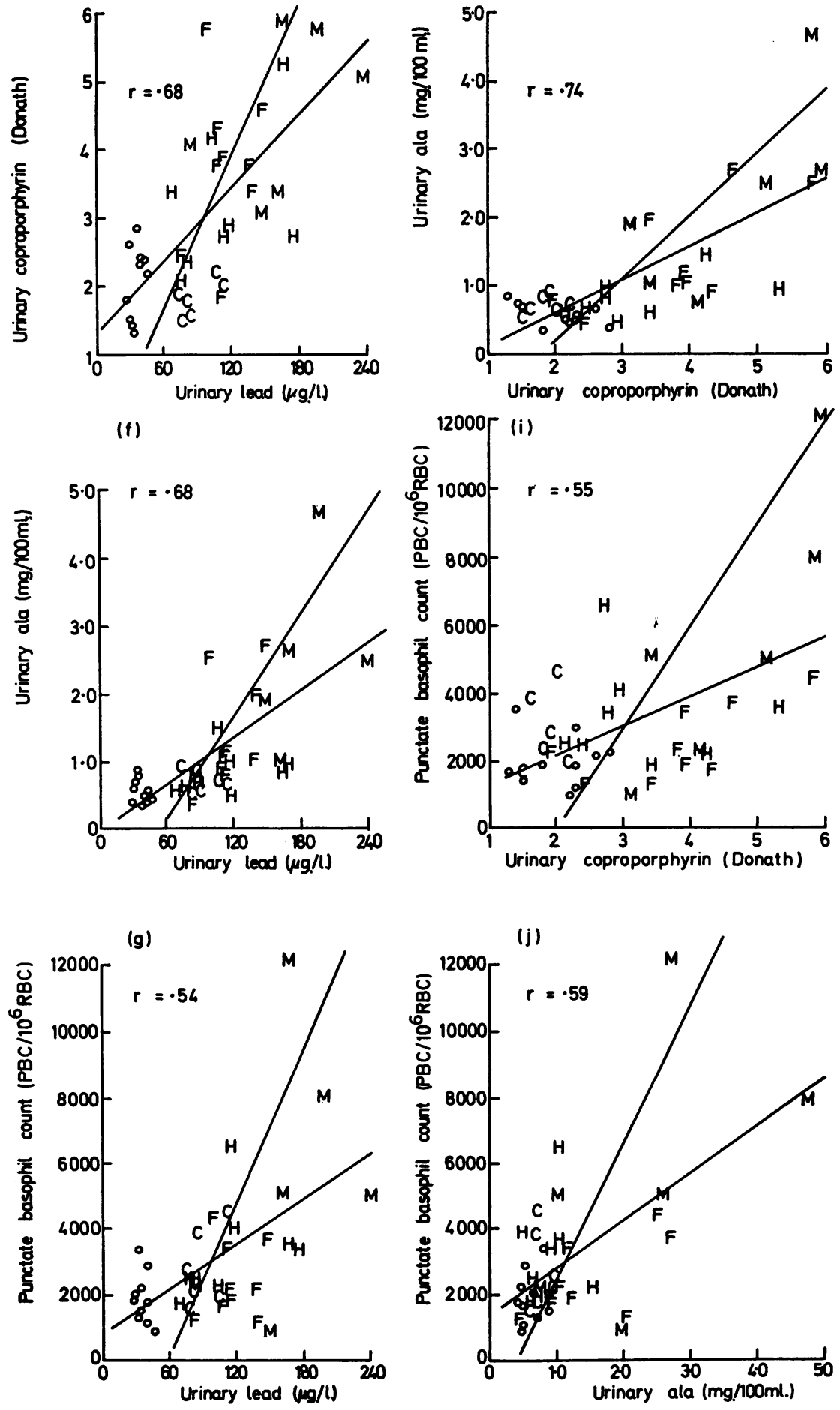
TABLE 7

Correlation Coefficients of Pairs of BIOCHEMICAL TESTS

\begin{tabular}{l|c|c|r|r|r}
\hline & $B L$ & $U L$ & $U C P$ & $A L A$ & $P B C$ \\
\hline UL & 0.90 & & & & \\
UCP & 0.79 & 0.68 & & & \\
ALA & 0.68 & 0.68 & 0.74 & & \\
PBC & 0.54 & 0.54 & 0.55 & 0.59 & \\
Hb & 0.16 & 0.003 & -0.06 & -0.12 & -0.04 \\
\hline
\end{tabular}

Abbreviations as in Table 3.

TABLE 8

Regression Equations $(X, Y)$ for Pairs of BIOCHEMICAL TESTS $(x, y)$

\begin{tabular}{|c|c|c|c|c|c|}
\hline$x$ & $y$ & & $X$ & & $Y$ \\
\hline $\begin{array}{l}\text { BL } \\
\text { BL } \\
\text { BL } \\
\text { BL } \\
\text { UL } \\
\text { UL } \\
\text { UL } \\
\text { UCP } \\
\text { UCP } \\
\text { ALA }\end{array}$ & $\begin{array}{l}\text { UL } \\
\text { UCP } \\
\text { ALA } \\
\text { PBC } \\
\text { UCP } \\
\text { ALA } \\
\text { PBC } \\
\text { ALA } \\
\text { PBC } \\
\text { PBC }\end{array}$ & $\begin{array}{l}21 \cdot 5 \\
13 \cdot 7 \\
35 \cdot 5 \\
39 \cdot 0 \\
15 \cdot 8 \\
52 \cdot 5 \\
57 \cdot 4 \\
1 \cdot 80 \\
2 \cdot 04 \\
0 \cdot 394\end{array}$ & $\begin{array}{l}+0.333 y \\
+12.1 y \\
+14.5 y \\
+0.00466 y \\
+26.7 y \\
+39.5 y \\
+0.0130 y \\
+1.11 y \\
+0.00033 y \\
+0.00024 y\end{array}$ & $\begin{array}{c}-35 \cdot 4 \\
0 \cdot 530 \\
-0.486 \\
-279 \\
1.34 \\
-0.004 \\
807 \\
-0 \cdot 384 \\
312 \\
1398\end{array}$ & $\begin{array}{l}+2 \cdot 46 \mathrm{x} \\
+0 \cdot 0518 \mathrm{x} \\
+0 \cdot 0321 \mathrm{x} \\
+62 \cdot 7 \mathrm{x} \\
+0 \cdot 0176 \mathrm{x} \\
+0 \cdot 0116 \mathrm{x} \\
+22 \cdot 9 \mathrm{x} \\
+0 \cdot 494 \mathrm{x} \\
+891 \mathrm{x} \\
+1453 \mathrm{x}\end{array}$ \\
\hline
\end{tabular}

Abbreviations as in Table 3.

subjects about regression. The possibility arises that, unless the variation between subjects is taken into account, excessive confidence may be placed, for example, in blood lead as an index of exposure, due to its low variation within subjects.

In order to reduce the effect of variation within subjects, more samples may be taken. It can be seen that urinary lead, urinary ALA, and the punctate basophil count will gain most. In the case of urinary samples, analysis will be simplified if several daily spot samples are pooled, or collected cumulatively. This is analogous to the collection of 24-hour samples, but, in industry, it is easier to arrange.

Associations of the biochemical tests HaegerAronsen (1960b) obtained correlation coefficients of 0.92 between urinary lead and ALA, 0.68 between urinary lead and coproporphyrin, and 0.37 between urinary lead and punctate basophil count. The first of these is higher than 0.68 found here possibly because Haeger-Aronsen studied more workers exposed to a wider range of lead absorption. Cramér and Selander (1965) studied 15 cases of lead poisoning with a wide range of biochemical test results and found correlation coefficients of 0.68 between urinary lead and ALA, of 0.72 between urinary lead and coproporphyrin, and of 0.65 between urinary ALA and coproporphyrin, broadly similar to the present results. Selander, Cramér, and Hallberg (1966) also found in 15 lead workers withdrawn from exposure for at least one week a correlation coefficient of 0.90 between blood lead and urinary ALA. The lower figure of 0.68 found here may be due to the smaller range, or greater number, of the readings. The regression equations were approximately similar.

In addition to factors such as respiratory minute volume and particle size already mentioned, the correlation of the biochemical tests with lead exposure estimated by personal sampler might be influenced by the nose-lapel distance of the sampling head, and by the oral ingestion of lead, both occupational and dietary, of the men in the survey. It is not known whether these factors, or 'metabolic' differences between men, were major contributors to the residual variation of the biochemical tests between subjects about regression. But it is of interest that both blood lead and urinary coproporphyrin were found to correlate as highly with lead-in-air $(0.90$ and 0.82 respectively) as they did with other biochemical tests (Tables 4 and 7 ).

\section{Correction for specific gravity of urinary lead and urinary ALA estimations}

Of the 195 total possible samples collected between 0900 and 1000 hours for urinary lead, four were of low volume, one was missed and one was lost, as described previously. The mean specific gravity of the remaining 189 samples was $1 \cdot 0198$. Excluding the nine samples with specific gravity less than 1.010 (Barnes, 1939; Webster, 1941; Molyneux, 1964), the mean specific gravity was $1 \cdot 0205$.

The mean specific gravity of 195 samples collected between 1200 and 1300 hours for urinary coproporphyrin and ALA was 1.0227 or 1.0228 excluding the two samples of specific gravity less than 1.010.

The variation within subjects from day to day and the residual variation between subjects about regression were calculated for urinary lead not corrected for specific gravity and urinary ALA corrected to specific gravity of 1.024 , and compared with the corrected and uncorrected results, respectively, already described. The results, given in Table 9, show that correction for specific gravity reduced the variation within subjects of urinary ALA but not of urinary lead. The reduction of the former was significant at the $5 \%$ level. Correction for specific gravity reduced the variation between subjects of both urinary lead and ALA, though neither difference was significant at the $5 \%$ level.

The correlation coefficients of uncorrected urinary lead, and corrected urinary ALA, with lead-in-air and the other biochemical tests were calculated and 
TABLE 9

Variation within Subjects from Day to Day, and Residual Variation between SubJects ABOUt REgression ON LEAD-IN-AIR OF URINARY LEAD (UL) AND URINARY ALA CORRECTED (COR) AND UNCORRECTED (UNCOR) FOR SPECIFIC GRAVITY

\begin{tabular}{|c|c|c|c|c|c|c|c|c|c|}
\hline Test & Units & \multicolumn{4}{|c|}{ Within subjects variation } & \multicolumn{4}{|c|}{ Between subjects variation } \\
\hline $\begin{array}{l}\text { UL cor } \\
\text { UL uncor }\end{array}$ & $\begin{array}{l}\mu \mathrm{g} . / 1 . \\
\mu \mathrm{g} . / 1 .\end{array}$ & $\begin{array}{l}31 \cdot 1 \\
25 \cdot 5\end{array}$ & $\begin{array}{l}1 \cdot 8 \\
1 \cdot 5\end{array}$ & $\begin{array}{l}31 \cdot 9 \\
31 \cdot 4\end{array}$ & $\begin{array}{l}1.9 \\
1.9\end{array}$ & $\begin{array}{l}65 \cdot 3 \\
61 \cdot 3\end{array}$ & $\begin{array}{l}7 \cdot 7 \\
7 \cdot 1\end{array}$ & $\begin{array}{l}67 \cdot 1 \\
75 \cdot 5\end{array}$ & $\begin{array}{l}7 \cdot 8 \\
8 \cdot 8\end{array}$ \\
\hline $\begin{array}{l}\text { ALA cor } \\
\text { ALA uncor }\end{array}$ & $\begin{array}{l}\mathrm{mg} . / 100 \mathrm{ml} . \\
\mathrm{mg} . / 100 \mathrm{ml} .\end{array}$ & $\begin{array}{l}0.26 \\
0.35\end{array}$ & $\begin{array}{l}0.02 \\
0.02\end{array}$ & $\begin{array}{l}21 \cdot 4 \\
31 \cdot 1\end{array}$ & $\begin{array}{l}1 \cdot 2 \\
1 \cdot 8\end{array}$ & $\begin{array}{l}1 \cdot 37 \\
1.46\end{array}$ & $\begin{array}{l}0 \cdot 17 \\
0 \cdot 17\end{array}$ & $\begin{array}{l}115 \cdot 3 \\
130 \cdot 8\end{array}$ & $\begin{array}{l}13 \cdot 4 \\
15.2\end{array}$ \\
\hline
\end{tabular}

$s=$ standard deviation $\quad C V=$ coefficient of variation $\quad S E=$ standard error.

TABLE 10

Correlation Coefficients of Urinary Lead (UL) AND Urinary ALA, Corrected (COR) AND UNCORRECTED (UNCOR) FOR SPECIFIC GRAVITY, WITH LEAD-IN-AIP. AND WITH THE OTHER BIOCHEMICAL TESTS

\begin{tabular}{|c|c|c|c|c|c|c|c|c|c|c|c|}
\hline & & & & & $P b$-in-air & $B L$ & $U L$ cor & $U C P$ & $A L A$ cor & $P B C$ & $H b$ \\
\hline $\begin{array}{l}\text { UL cor } . . \\
\text { UL uncor. }\end{array}$ & $\begin{array}{l}\cdots \\
\cdots\end{array}$ & $\begin{array}{l}\cdots \\
\cdots\end{array}$ & $\begin{array}{l}\cdots \\
\cdots\end{array}$ & $\begin{array}{l}\cdots \\
\cdots\end{array}$ & $\begin{array}{l}0.82 \\
0.76\end{array}$ & $\begin{array}{l}0.90 \\
0.84\end{array}$ & $\ddot{x}$ & $\begin{array}{l}0 \cdot 68 \\
0 \cdot 59\end{array}$ & $\begin{array}{l}0.72 \\
0.67\end{array}$ & $\begin{array}{l}0.54 \\
0.50\end{array}$ & $\begin{array}{r}0.003 \\
-0.03\end{array}$ \\
\hline $\begin{array}{l}\text { ALA cor } \\
\text { ALA uncor }\end{array}$ & $\begin{array}{l}\cdots \\
\cdots\end{array}$ & $\begin{array}{l}\cdots \\
.\end{array}$ & $\begin{array}{l}. . \\
.\end{array}$ & $\begin{array}{l}. . \\
\cdots\end{array}$ & $\begin{array}{l}0.74 \\
0.68\end{array}$ & $\begin{array}{l}0.72 \\
0.68\end{array}$ & $\begin{array}{l}0.72 \\
0.68\end{array}$ & $\begin{array}{l}0.78 \\
0.74\end{array}$ & $\begin{array}{l}\cdots \\
\cdots\end{array}$ & $\begin{array}{l}0.60 \\
0.59\end{array}$ & $\begin{array}{l}-0 \cdot 13 \\
-0.12\end{array}$ \\
\hline
\end{tabular}

compared with the corrected, and uncorrected results, respectively, described previously. The results, in Table 10, show that for both urinary lead and ALA, correction for specific gravity increased every correlation coefficient except those with haemoglobin.

A method for estimating the comparative merits of tests of lead exposure has been described previously (Williams et al., 1968a). The method has been used to calculate the comparative merits of individual readings of both urinary lead and urinary ALA corrected and uncorrected for specific gravity. The results, given in Table 11 , show that the merits were increased by correcting for specific gravity, though neither increase was statistically significant at the $5 \%$ level.

\section{Discussion}

Many attempts have been made to account for and reduce the variation of urinary lead estimations. Twenty-four-hour and three-day samples have been collected, results have been expressed as functions of volume and of time, and correction has been made for creatinine concentration, urinary clearance, specific gravity, diurnal variation, and osmolality (Kehoe, Thamann, and Cholak, 1933; Barnes, 1939; Kehoe, Cholak, Hubbard, Bambach, McNary, and Story, 1940; Pinto, Elkins, and Ege, 1941; Webster, 1941; Molyneux, 1964; Elkins and
TABLE 11

Comparative Merit ( $z$ ), with Standard Error $(S E(z))$ AND $95 \%$ CONFIDENCE LIMITS, OF Urinary LeAD AND URINARY ALA, CoRrected (COR) AND UNCORRECTED (UNCOR) FOR SPECIFIC GravitY

\begin{tabular}{|c|c|c|c|c|c|}
\hline & & & $z$ & $S E(z)$ & $\begin{array}{c}95 \% \\
\text { Confidence } \\
\text { !imits }\end{array}$ \\
\hline $\begin{array}{l}\text { UL cor. . } \\
\text { UL uncor }\end{array}$ & $\begin{array}{l}\cdots \\
\cdots\end{array}$ & $\begin{array}{l}\cdots \\
\cdots\end{array}$ & $\begin{array}{l}9 \cdot 67 \\
7 \cdot 83\end{array}$ & $\begin{array}{l}1 \cdot 58 \\
1 \cdot 43\end{array}$ & $\begin{array}{l}6 \cdot 50-12 \cdot 84 \\
4 \cdot 97-10 \cdot 70\end{array}$ \\
\hline $\begin{array}{l}\text { ALA cor } \\
\text { ALA uncor }\end{array}$ & $\begin{array}{l}\cdots \\
\cdots\end{array}$ & $\begin{array}{l}\cdots \\
\cdots\end{array}$ & $\begin{array}{l}7 \cdot 22 \\
6 \cdot 13\end{array}$ & $\begin{array}{l}1 \cdot 37 \\
1 \cdot 30\end{array}$ & $\begin{array}{l}4.47-9.97 \\
3.53-8.73\end{array}$ \\
\hline
\end{tabular}

Pagnotto, 1966). Correction for urinary specific gravity was recommended by Levine and Fahy (1945), Molyneux (1964), and Elkins and Pagnotto (1965) but not by Ellis (1966), who studied the variation within subjects of serial (consecutive) samples from five hospital in-patients.

Urinary ALA excretion has been expressed in terms of time, volume, and creatinine concentration (Haeger-Aronsen, 1960a; de Kretser and Waldron, 1963; Cramér and Selander, 1967) but apparently has not been corrected for specific gravity though Rainsford (1961) suggested the procedure for urinary coproporphyrin. 
Unlike the collection of 24-hour samples and the estimation of creatinine, measurement of specific gravity is simple and readily adopted in a screening test of lead workers. The present results, though not statistically significant, suggest that some benefit may be obtained when spot samples of urine for lead and ALA estimation, taken at the same times of day, are corrected for specific gravity. If samples having specific gravity less than 1.010 are to be excluded, the specific gravity must be determined in any case.

The standard specific gravity chosen varies. In the United States the figure of 1.024 has been found in men at work by Levine and Fahy (1945) and is still used (Elkins and Pagnotto, 1965). Rainsford (1961) in Eire and Buchwald $(1964 ; 1965)$ in England recommended a specific gravity of 1.016 but the former study was based on 24-hour samples and in neither study were the samples collected specifically from men at work. In the present survey the mean specific gravities at 0900 to 1000 hours and 1200 to 1300 hours were about 1.020 and 1.022 respectively, though the former result may have been influenced by the request to limit excessive fluid intake beforehand.

The absolute value of the standard chosen matters only when corrected and uncorrected results are compared, an uncommon occurrence. But the value of the standard has considerable relative importance when the findings of different investigators are compared. For example, a urinary lead estimation of $200 \mu \mathrm{g}$./l. corrected to 1.024 would be $133 \mu \mathrm{g}$. $/ \mathrm{l}$. corrected to 1.016 . For these reasons it seems desirable that the standard originally adopted by Levine and Fahy (1945) of 1.024 should be retained until evidence is produced that a change would be generally beneficial.

\section{Conclusions}

Lead exposure, measured by personal sampler, of men selected as suitable for employment and doing almost identical work differed by ratios of as much as four to one. This could be attributed only to personal differences in working habits.

The correlation coefficients and regression equations of blood lead, urinary lead, urinary coproporphyrin, urinary ALA, the punctate basophil count and haemoglobin, with lead-in-air and with each other were calculated. Using the regression equations, the mean values and $95 \%$ confidence limits of some of the biochemical tests corresponding to the two TLVs of lead-in-air were calculated.

For each biochemical test the variation due to analytical error, the variation from day to day within subjects, and the residual variation between subjects about regression on lead-in-air were calculated. Previous estimates of the latter are not known.
Excessive confidence may be placed, for example, in blood lead as an index of exposure due to its low coefficient of variation within subjects $(9 \cdot 3 \%)$ unless the coefficient of variation between subjects about regression $(39.4 \%)$ is taken into account.

The correction, for specific gravity, of estimations of lead and ALA in spot samples of urine was found to reduce slightly the residual variation between subjects about the regression on lead-in-air and to increase the correlations with lead-in-air and with the other biochemical tests, but these changes were not statistically significant.

We are very grateful to the 40 employees of Electric Power Storage Company, Ltd., Dagenham, who took part in the survey. We are also very grateful to Sister Margaret Smith for haemoglobin estimations; to Mrs. Lilian White for punctate basophil counts; to Mr. J. Few, Mr. T. J. Forward, and Mr. M. Mohuiddin for assistance with urinary ALA estimations; to Mr. J. Hay for assistance with personal samplers; and to Miss Linda South for computing assistance. Figure 1 is reproduced by courtesy of the Editor of the British Medical Journal. Finally, we are indebted to Dr. D. Malcolm and the Directors of the Electric Power Storage Company, Ltd., for permission to undertake the survey, and for financial assistance; and to many other members of the Company for help and co-operation.

\section{References}

American Conference of Governmental Industrial Hygienists. (1960). Threshold limit values for 1960. Arch. environm. Hlth, 1, 140-144. - (1965). Threshold limit values for 1965. A.C.G.I.H., 1014 Broadway, Cincinnati, Ohio.

American Industrial Hygiene Association. (1960). Lead and its inorganic compounds. Hygienic Guide Series, A.I.H.A., 14125 Prevost, Detroit 27, Michigan.

American Public Health Association. (1943). Occupational Lead Exposure and Lead Poisoning, a report prepared by the committee on lead poisoning of the Industrial Hygiene Section of the A.P.H.A., 1790 Broadway, New York. (a) p. 11 et seq.; (b) p. 17.

Barnes, E. C. (1939). Possibilities of control of lead exposure by examining less than 24 hour urine samples. J. industr. Hyg., 21 , 464-468.

Buchwald, H. (1964). The expression of urine analysis resultsobservations on the use of a specific gravity correction. Ann. occup. Hyg., 7, 125-136.

(1965). The specific gravity of urine specimens. Ibid., 8, 265.

Casella \& Co. (1966). Personal Air Sampler. Leaflet 930/5/AR, C. F. Casella \& Co., Ltd., Regent House, Britannia Walk, London, N.1.

Cramér, K. (1966). Predisposing factors for lead poisoning. Acta med. scand., Supplement 445, 56-59.

, and Selander, S. (1965). Studies in lead poisoning. Brit. J. industr. Med., 22, 311-314.

-1 - (1967). Control of lead workers by determination of urinary 8-aminolaevulinic acid. Ibid., 24, 283-288.

Documenta Geigy (1962). Scientific Tables. 6th ed., p. 578. Geigy Pharmaceutical Co., Manchester.

Donath, W. F. (1956). A simple portable apparatus for the semiquantitative determination of the coproporphyrin content in urine. Arh. Hig. Rada, 7, 77-84.

Dreessen, W. C., Edwards, T. I., Reinhart, W. H., Page, R. T., Webster, S. H., Armstrong, D. W., and Sayers, R. R. (1941). The control of the lead hazard in the storage battery industry. United States Public Health Service. Publ. Hlth Bull. (Wash.), No. 262.

Elkins, H. B. (1959). The Chemistry of Industrial Toxicology. 2nd ed., p. 49 et seq. Wiley, New York; Chapman and Hall, London.

, and Pagnotto, L. D. (1965). Is the 24-hour urine sample a fallacy? Amer. industr. Hyg. Ass. J., 26, 456-460. 
(1966). The osmolality adjustment in urinalysis. $J$. occup. Med., 8, 528-531.

Ellis, R. W. (1966). Urinary screening tests to detect excessive lead absorption. Brit. J. industr. Med., 23, 263-281.

Goldberg, A., Smith, J. A., and Lochhead, A. (1963). Treatment of lead-poisoning with oral penicillamine. Brit. med. J., 1, 1270-1275.

Goldwater, L. J., and Hoover, A. W. (1967). An international study of 'normal' levels of lead in blood and urine. Arch. environm. Hlth, 15, 60-63.

Haeger-Aronsen, Birgitta. (1960). Studies on urinary excretion of $\delta$-aminolaevulic acid and other haem precursors in lead workers and lead-intoxicated rabbits. Scand. J. clin. Lab. Invest., 12 Suppl. 47, (a) p. 47; (b) pp. 85-87.

Hamilton, Alice. (1919). Lead poisoning in American industry. J. industr. Hyg., 1, 8-21.

Hofreuter, D. H., Catcott, E. J., Keenan, R. G., and Xintaras, C. (1961). The public health significance of atmospheric lead. Arch. environm. Hlth, 3, 568-574.

Holeček, V., and Péničková, M. (1957). Part I: Level of the precursor of coproporphyrin and preformed coproporphyrin in fresh urine. Part II: Distribution of urinary coproporphyrin isomers I and II. Brit. J. industr. Med., 14, 198-208.

Kehoe, R. A. (1961). The metabolism of lead in man in health and disease.-The Harben Lectures, 1960. J. roy Inst. publ. Hlth, 24, 81-97, 101-120, 129-143.

(1962). Industrial Lead Poisoning. Chapter XXVI in Industrial Hygiene and Toxicology by Patty, F. A., 2nd ed., Vol. 2, Toxicology, pp. 941-985. Interscience Publishers, John Wiley, New York. (1965). Contaminated and natural lead environments of man Arch. environm. Hlth, 11, 736-739.

—- Cholak, J., Hubbard, D. M., Bambach, K., McNary, R. R., and Story, R. V. (1940). Experimental studies on the ingestion of lead compounds. J. industr. Hyg., 22, 381-400.

- Thamann, F., and Cholak, J. (1933). On the normal absorption and excretion of lead. Ibid., 15, 257-305.

King, E., and Thompson, A. R. (1961). The measurement of lead absorption in industry. Ann. occup. Hyg., 3, 247-263.

Kretser, A. J. de, and Waldron, H. A. (1963). Urinary $\delta$-aminolaevulinic acid and porphobilinogen in lead-exposed workers. Brit. J. industr. Med., 20, 35-40.

Lane, R. E. (1931). The role of punctate basophilia in the control of industrial plumbism. J. ind $\nu$ str. Hyg., 13, 276-284.

(1949). The care of the lead worker. Brit. J. industr. Med., 6, 125-143.

Legge, T. M., and Goadby, K. W. (1912). Lead Poisoning and Lead Absorption: the Symptoms, Pathology and Prevention, with Special Reference to their Industrial Origin and an Account of the Principle Processes Involving Risk, p. 27 et seq. Edward Arnold, London; Longmans Green, New York.

Levine, L., and Fahy, J. P. (1945). Evaluation of urinary lead determinations. I. The significance of the specific gravity. $J$. industr. Hyg., 27, 217-223.

Mauzerall, D., and Granick, S. (1956). The occurrence and determination of $\delta$-aminolevulinic acid and porphobilinogen in urine. J. biol. Chem., 219, 435-446.

Molyneux, M. K. B. (1964). Use of single urine samples for the assessment of lead absorption. Brit. J. industr. Med., 21, 203-209.

Pinto, S. S., Elkins, H. B., and Ege, J. F. (1941). Renal excretion of industrial chemicals. I. Urinary-lead concentration and blood-lead clearance. J. industr. Hyg., 23, 313-321.

Rainsford, S. G. (1961). Pathologic aids in the supervision of lead workers. Proc. XIIIth int. Congr. occup. Hlth, New York, 1960 pp. 345-348.

Roach, S. A. (1966a). The null-point method for measuring the flow-rate in a sampling train. Amer. industr. Hyg. Ass. J., 27, 135-139.

(1966b). A more rational basis for air sampling programs. Ibid., 27, 1-12.

Russell, A. E., Jones, R. R., Bloomfield, J. J., Britten, R. H., and Thompson, L. R. (1933). Lead Poisoning in a Storage Battery Plant. United States Public Health Service. Publ. Hlth Bull. (Wash.), No. 205.

Selander, S., Cramér, K., and Hallberg, L. (1966). Studies in lead poisoning-oral therapy with penicillamine: relationship between lead in blood and other laboratory tests. Brit. J. industr. Med. 23, 282-291.
Shiels, D. O., Palmer, G. R., Cornish, P. E., and Kearley, E. J. (1953) Porphyrinuria in persons exposed to lead hazards. Med. J. Aust., 2, 171-176.

Tsuchiya, K., and Harashima, S. (1965). Lead exposure and the derivation of maximum allowable concentrations and threshold limit values. Brit. J. industr. Med., 22, 181-186.

Watson, C. J., and Larson, E. A. (1947). The urinary coproporphyrins in health and disease. Physiol. Rev., 27, 478-510.

Webster, S. H. (1941). Diurnal variation of urinary lead excretion. Publ. Hlth Rep. (Wash.), 56, 1834-1848.

Williams, M. K. (1967). The measurement of lead absorption. Thesis submitted for the Degree of Doctor of Medicine in the University of Oxford.

, and Few, J. D. (1967). A simplified procedure for the determination of urinary $\delta$-aminolaevulinic acid. Brit. J. industr. Med. 24, 294-296.

- King, E., and Walford, Joan (1968a). Method for estimating objectively the comparative merits of biological tests of lead exposure. Brit. med. J., 1, 618-621.

, Walford, J., and King, E. (1968b). A trial of terylene overalls for lead-acid electric accumulator pasters. Brit. J. industr. Med., 25, 144-147.

Zielhuis, R. L. (1958). Methods of counting basophil punctated erythrocytes in lead intoxication. Proc. XIIth int. Congr. occup. Hlth, Helsinki, 1957. Vol. 3, pp. 290-292.

- (1961). Coproporphyrinuria in groups of workers as an index of inorganic lead absorption. Brit. J. industr. Med., 18, 58-62.

\section{Appendix}

\section{Estimation of blood lead and urinary lead}

Method Estimations were made by a modification of the method of King and Thompson (1961). Using $3 \mathrm{ml}$. blood, or $20 \mathrm{ml}$. urine, with standardized reagent additions, the procedure was carried out in a single boiling tube, without transfer. The absorbance was then read in a Unicam SP 500 spectrophotometer in 2-cm. path cells at $515 \mathrm{~nm}$.

Accuracy A total of 66 blood samples containing known amounts of added lead was analysed in three series during six months. In each series the mean absorption of four reagent blanks was subtracted from the absorptions observed and the lead content of the blood pool calculated from the slope of the remaining absorptions against the added lead. Samples were expressed as $\mu \mathrm{g}$. lead/100 ml. blood, and ranged from $23 \mu \mathrm{g} . / 100 \mathrm{ml}$. to $163 \mu \mathrm{g} . / 100 \mathrm{ml}$. Assuming linearity, it was calculated that

$\mu$ g. lead $/ 100 \mathrm{ml}$. blood $=0.58$ (absorbance $\times 100$ ) and the standard error of an estimate $=2.6 \mu \mathrm{g}$. lead/100 ml. blood.

Specificity With the buffering and complexing reagents used, bismuth is the only commonly occurring substance likely to interfere. It causes a brown discoloration of the pink lead dithizonate and may be confirmed by measuring the absorbance at $490 \mathrm{~nm}$ as well as at $515 \mathrm{~nm}$. But such interference has not been observed in 20,000 estimations.

Received for publication November 19, 1968 